\title{
Correction to: Effects of relaxation on self-esteem of patients with cancer: a randomized clinical trial
}

\author{
Mehdi Harorani ${ }^{1}$ - Masoomeh Noruzi Zamenjani ${ }^{1} \cdot$ Mohamad Golitaleb $^{1} \cdot$ Fahimeh Davodabady ${ }^{1} \cdot$ Sima Zahedi $^{1}$. \\ Ali Jadidi $^{2} \cdot$ Masoud Rezaei $^{3}$
}

Published online: 5 September 2019

(C) Springer-Verlag GmbH Germany, part of Springer Nature 2019

\section{Correction to: Support Care Cancer https://doi.org/10.1007/s00520-019-05025-3}

The article Effects of relaxation on self-esteem of patients with cancer: a randomized clinical trial, written by Mehdi Harorani, Masoomeh Noruzi Zamenjani, Mohamad Golitaleb, Fahimeh Davodabady, Sima Zahedi, Ali Jadidi and Masoud Rezaei, was originally published electronically on the publisher's internet portal (currently SpringerLink) on 16 August 2019 with open access. With the author(s)' decision to step back from Open Choice, the copyright of the article changed on 06 September 2019 to (C) Springer-Verlag GmbH Germany, part of Springer Nature 2019 and the article is forthwith distributed under the terms of copyright.

The original article has been corrected.

Publisher's note Springer Nature remains neutral with regard to jurisdictional claims in published maps and institutional affiliations.

The online version of the original article can be found at https://doi.org/ $10.1007 / \mathrm{s} 00520-019-05025-3$

Masoud Rezaei

Masoud.Rezaei68@yahoo.com

1 Faculty of Nursing and Midwifery, Department of Nursing, School of Nursing and Midwifery, Arak University of Medical Sciences, Arak, Iran

2 Chronic Diseases (Home Care) Research Center, Hamadan University of Medical Sciences, Hamadan, Iran

3 Nursing Care Research Center (NCRC), School of Nursing and Midwifery, Iran University of Medical Sciences, Tehran, Iran 